The Journal of Bone E Joint Surgery
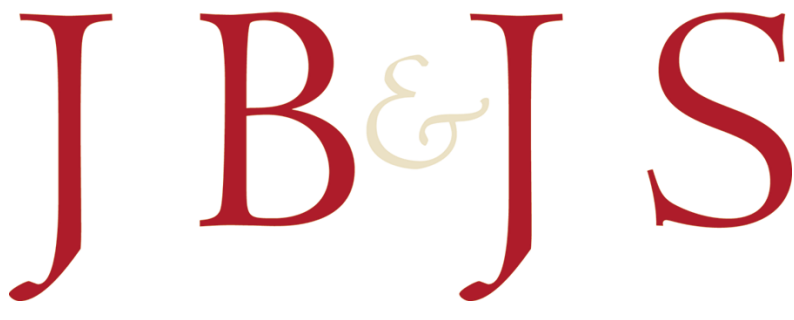

This is an enhanced PDF from The Journal of Bone and Joint Surgery

The PDF of the article you requested follows this cover page.

\title{
Novel Methods for Diagnosis and Treatment of Posterolateral Rotatory Instability of the Knee
}

Chong Bum Chang, Sang Cheol Seong, Sahnghoon Lee, Jae Ho Yoo, Yoon Keun Park and Myung Chul Lee J Bone Joint Surg Am. 2007;89:2-14. doi:10.2106/JBJS.G.00582

This information is current as of September 4, 2009

Reprints and Permissions

Click here to order reprints or request permission to use material from this article, or locate the article citation on jbjs.org and click on the [Reprints and Permissions] link.

Publisher Information

The Journal of Bone and Joint Surgery

20 Pickering Street, Needham, MA 02492-3157

www.jbjs.org 


\title{
Novel Methods for Diagnosis and Treatment of Posterolateral Rotatory Instability of the Knee
}

\author{
By Chong Bum Chang, MD, PhD, Sang Cheol Seong, MD, PhD, Sahnghoon Lee, MD, \\ Jae Ho Yoo, MD, Yoon Keun Park, MD, and Myung Chul Lee, MD, PhD
}

I troduction njury to the posterolateral corner structures of the knee can cause posterolateral rotatory instability, a condition that has attracted increased attention over recent years ${ }^{1}$. This injury is often associated with cruciate ligament injury, and its diagnosis can be difficult unless one has a high degree of clinical suspicion for an injury to the posterolateral corner structures $^{2,3}$. Although a number of treatment methods have been proposed over the past twenty years ${ }^{2,4-12}$, there has been considerable controversy regarding the optimal method of surgical treatment for this injury. The consequences of missed or unsuccessfully treated posterolateral rotatory instability can be profound: reconstructed anterior or posterior cruciate ligaments can fail, and persistent posterolateral rotatory instability may eventually cause pain, instability, and even degenerative changes ${ }^{13-17}$.

In this report, we describe the use of an external rotationvalgus stress radiograph for the evaluation and diagnosis of posterolateral rotatory instability, and we describe a new anatomical reconstruction procedure involving use of a split Achilles tendon allograft for its treatment.

\section{External Rotation-Valgus Stress Radiograph: \\ a New Radiographic Method for Objective \\ Documentation of Posterolateral Rotatory \\ Instability of the Knee \\ Background}

A lhough several physical examination techniques for the $A$ detection of posterolateral rotatory instability of the knee have been described ${ }^{18,19}$, no widely accepted method of objective documentation, such as the use of posterior stress radiographs to identify a posterior cruciate ligament injury, has been established for posterolateral rotatory instability. Consequently, assessment of posterolateral rotatory instability is very subjective and dependent on the examiner's experience. Several biomechanical studies have documented that sectioning of the posterolateral corner structures markedly increases external rotation of the tibia at $30^{\circ}$ of knee flexion, whereas sectioning of the posterior cruciate ligament alone does not have the same effect ${ }^{20-22}$. Consequently, increased external rotation of the tibia relative to the femur at $30^{\circ}$ of knee flexion has been regarded as a specific finding indicating posterolateral rotatory instability of the knee. Clinically, posterolateral rotatory instability of the knee refers to a ligamentous lesion that allows posterolateral subluxation of the tibial plateau $^{23}$. In addition, coupled valgus or posterior translation and an external rotational force have been found to increase the degree of posterolateral subluxation ${ }^{19,21}$. On the basis of these findings, we hypothesized that increased posterolateral subluxation of a knee with posterolateral rotatory instability could be demonstrated radiographically as increased lateral translation of the proximal part of the tibia in relation to the femur with an external rotation-valgus stress.

\section{Position and Technique for the External Rotation-Valgus Stress Radiograph}

Figures 1-A through 1-E show the position and technique used to make the external rotation-valgus stress radiograph. Stress radiography is performed with the subject in the supine position. The examiner grips the subject's heel with one hand, supports the lateral aspect of the thigh with the other, and flexes the knee to about $30^{\circ}$. The subject is then encouraged to relax, and the examiner rotates the distal part of the leg externally while applying a valgus stress to translate the proximal part of the tibia posterolaterally. The hip is internally rotated $20^{\circ}$, and an anteroposterior radiograph is made with the beam angled caudally $10^{\circ}$. Internal rotation of the hip allows the posterolateral translation to appear as lateral translation on

Disclosure: The authors did not receive any outside funding or grants in support of their research for or preparation of this work. Neither they nor a member of their immediate families received payments or other benefits or a commitment or agreement to provide such benefits from a commercial entity. No commercial entity paid or directed, or agreed to pay or direct, any benefits to any research fund, foundation, division, center, clinical practice, or other charitable or nonprofit organization with which the authors, or a member of their immediate families, are affiliated or associated. 
The JOURnAL OF BONE \& JOINT SURGERY • JBIS. ORG VOLUME 89-A · SUPPLEMENT $3 \cdot 2007$
Novel Methods for Diagnosis and Treatment of Posterolateral Rotatory Instability of the KneE the radiographs, and the caudal angle of the beam provides a tibial plateau view to facilitate measurement. During a pilot trial, we found that about $20^{\circ}$ of internal rotation of the hip and $10^{\circ}$ of caudal tilt of the radiographic tube were the optimal positions to provide the best image for measurement.
However, rather than requiring exact positioning of the limb by applying the same protocol (i.e., an identical amount of internal rotation of the hip and caudal tilt of the radiographic tube to the contralateral knee), a companion radiograph can be made to achieve the most accurate evaluation.

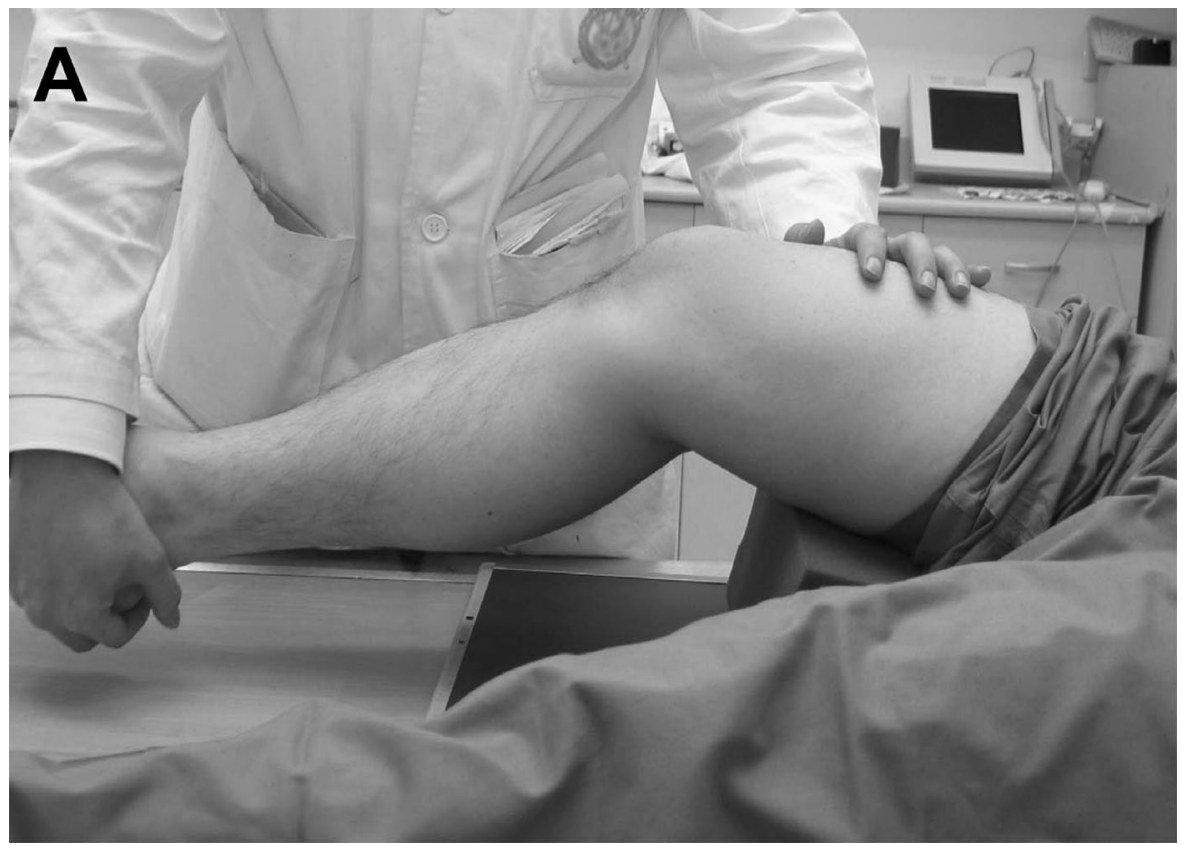

Fig. 1-A

Figs. 1-A through 1-E Position and technique for making the external rotation-valgus stress radiograph. Fig. 1-A The examiner grips the subject's heel with one hand, supports the lateral aspect of the thigh with the other, and flexes the knee to about $30^{\circ}$.

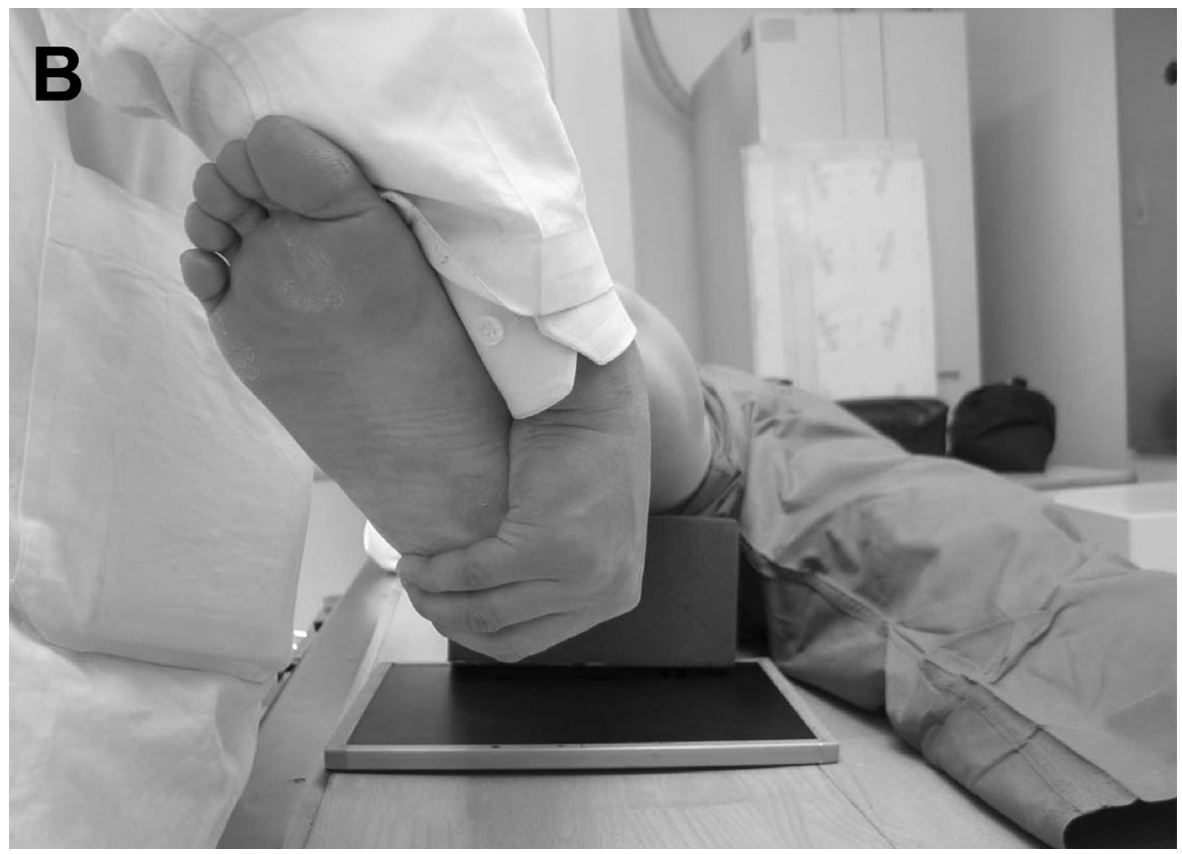

Fig. 1-B

An external rotation force is applied to the distal part of the leg. 


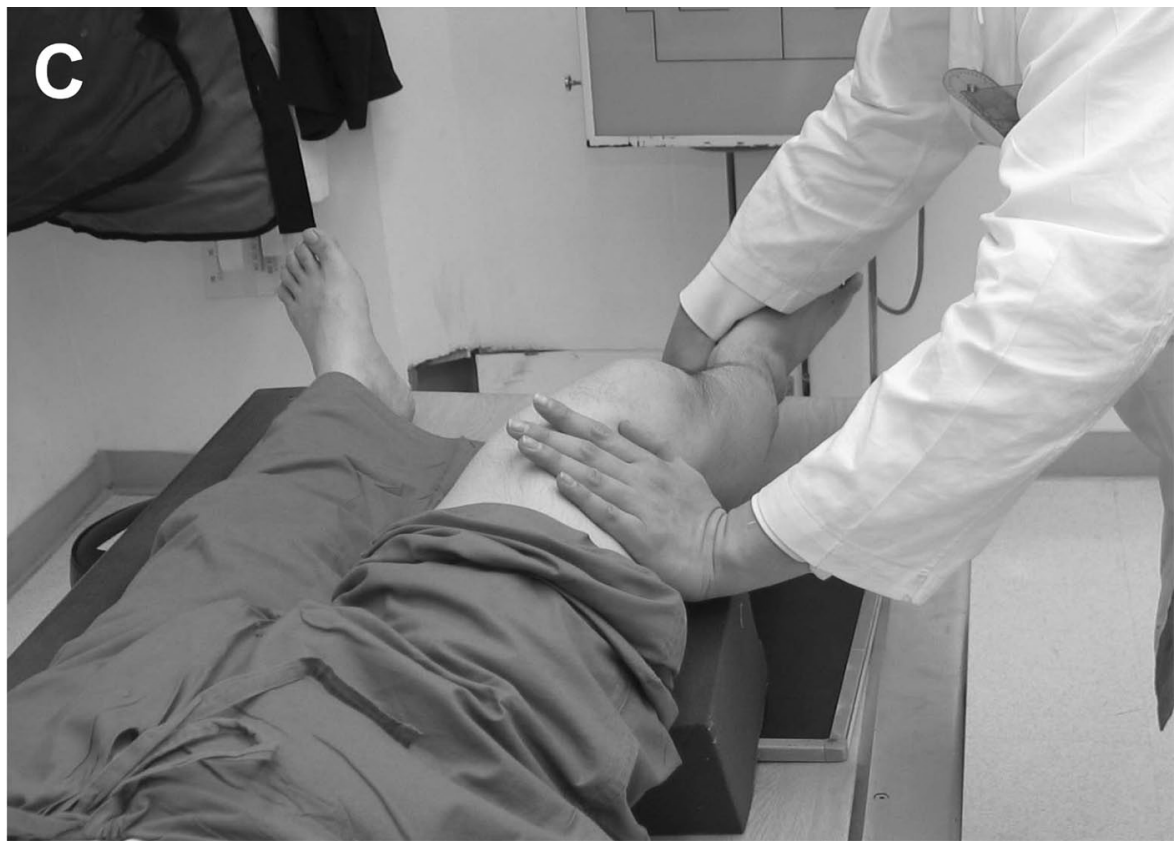

Fig. 1-C

A valgus stress is then applied to the knee to enhance the posterolateral translation of the prox-

imal part of the tibia.

\section{Materials and Methods}

From January 2004 to March 2006, seventeen consecutive patients diagnosed as having posterolateral rotatory instability and the same number of normal healthy volunteers were evaluated with the external rotation-valgus stress radiograph. The inclusion criteria for the patient group (the posterolateralrotatory-instability group) were (1) unilateral posterolateral rotatory instability with an uninjured contralateral knee, (2) $>10^{\circ}$ of side-to-side difference demonstrated by the tibial external rotation (dial) test at $30^{\circ}$ of knee flexion, and (3) a positive posterolateral drawer test. The inclusion criteria for the healthy volunteers (the control group) were (1) the absence of knee pain, (2) no history of knee injury and no obvious knee deformity, (3) $<5^{\circ}$ of side-to-side difference demonstrated by the tibial external rotation (dial) test at $30^{\circ}$ of knee flexion, (4) a negative posterolateral drawer test, and (5) a negative varus stress test at $0^{\circ}$ and $30^{\circ}$ of flexion. In addition, eight patients who were diagnosed as having a posterior cruciate ligament injury without evident posterolateral rotatory instability (the posterior-cruciate-injury group) were evaluated. Table I summarizes the characteristics of the three groups. This study was approved by the institutional review board of our hospital, and informed consent for the use of their medical information was obtained from all study subjects.

Before the stress radiographs were made, side-to-side differences in thigh-foot angles (as demonstrated with the dial test) at $30^{\circ}$ of knee flexion were determined for all subjects by two examiners. Angle measurements were carried out with use of a goniometer in triplicate by each examiner. Average values were regarded as true values.

To analyze the stress radiograph, two fixed landmarks

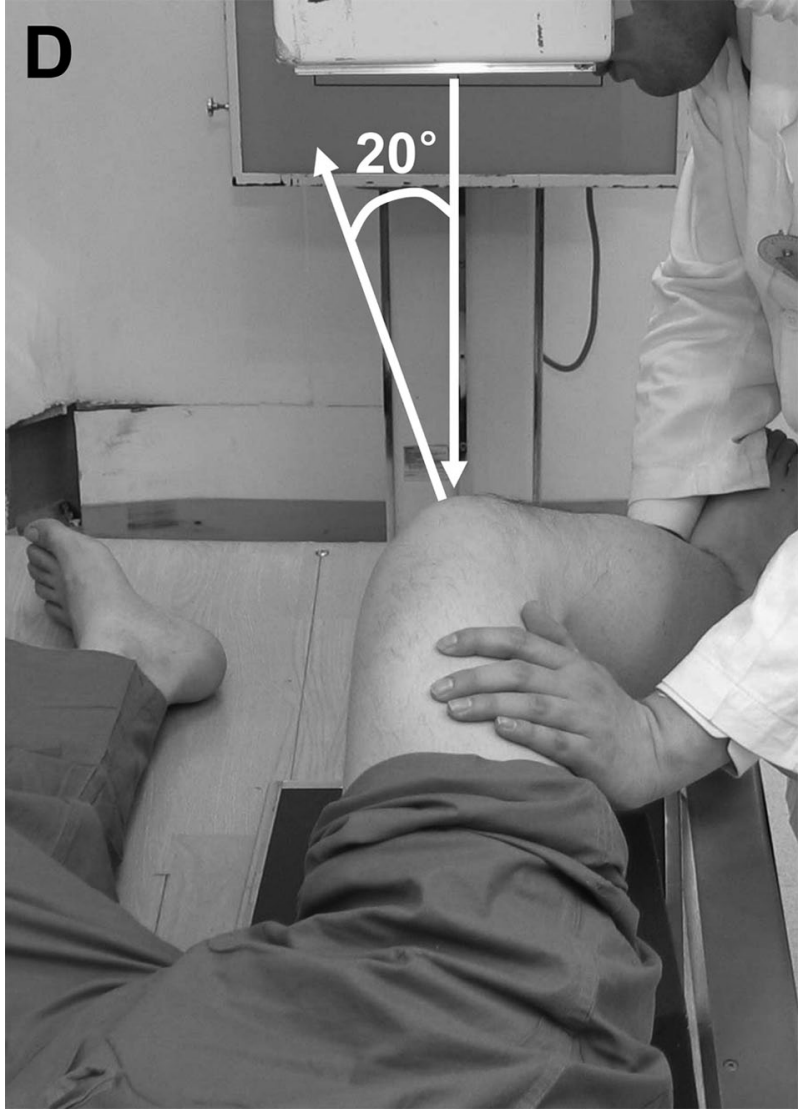

Fig. 1-D

The hip is internally rotated $20^{\circ}$ to allow the posterolateral translation to appear as lateral translation on the radiograph. 


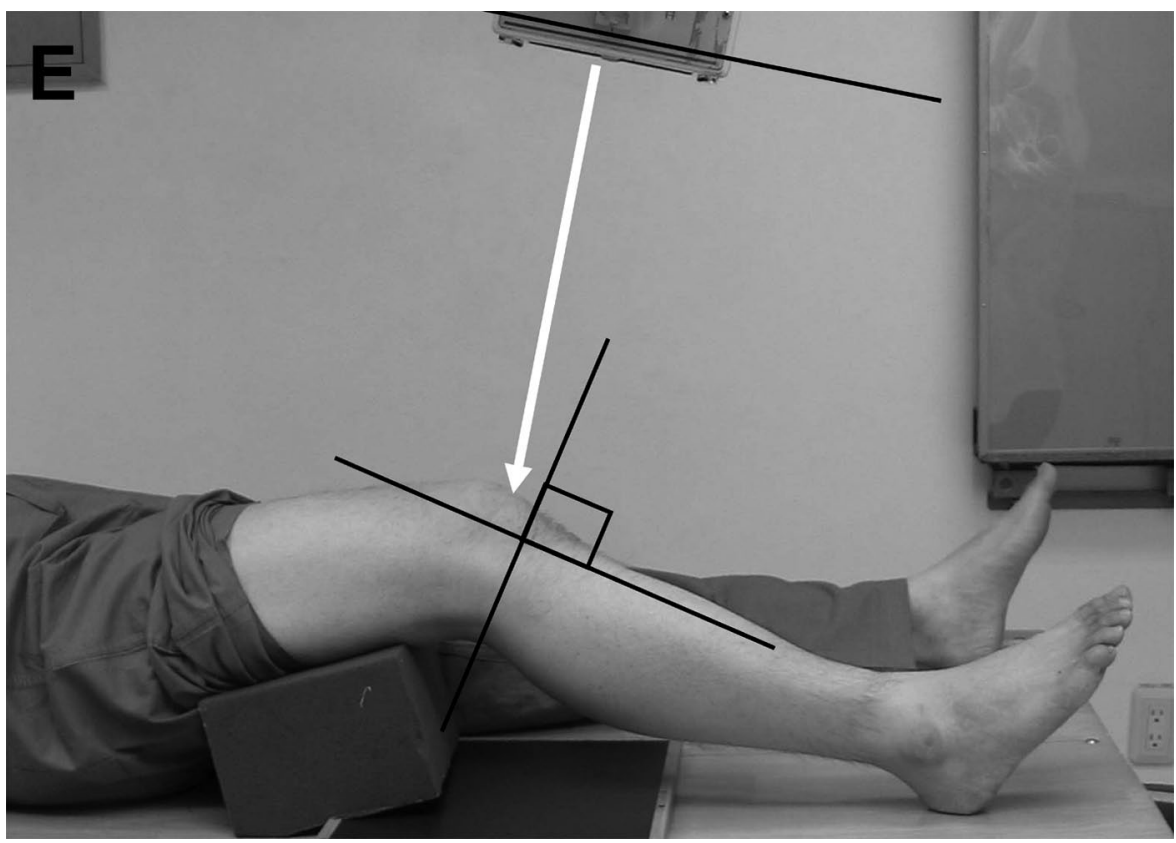

\section{Fig. 1-E}

Ten degrees of caudal tilt of the radiographic tube can produce a tibial plateau view, which is the best image for measurement.

were defined: the lateral edge of the lateral femoral condyle and the lateral border of the lateral tibial condyle. At first, a baseline connecting the medial and lateral edges of the tibial plateau was drawn, and then lines tangential to each landmark were drawn perpendicular to the baseline. The degree of lateral displacement of the proximal part of the tibia relative to the distal part of the femur was measured as the distance D (in millimeters) between the two tangential lines (Fig. 2). The side-to-side difference in displacement between the injured knee and the uninjured contralateral knee was then calculated. All measurements were performed with use of digital images, which were acquired with a picture archiving and communi- cation system (PACS) on a 21-in (53.3-cm) LCD (liquid crystal display) monitor (ME315L; Totoku, Nagaoka, Japan) with use of V-works software (version 5.0; CyberMed, Seoul, South Korea). This computerized system made it possible to carry out measurements on magnified images and allowed vertical lines to be easily drawn to the baseline. Measurements were performed by one of us (C.B.C.) and were repeated three times at intervals of two days. The average of the three measurements was regarded as the true value.

The intrarater reliability of the radiographic measurements was assessed with use of the intraclass correlation coefficient, which quantifies the variance of ratings-i.e., the

\begin{tabular}{|c|c|c|c|}
\hline & $\begin{array}{l}\text { Posterolateral-Rotatory- } \\
\text { Instability Group }\end{array}$ & $\begin{array}{l}\text { Normal Control } \\
\text { Group }\end{array}$ & $\begin{array}{l}\text { Posterior-Cruciate- } \\
\text { Injury Group }\end{array}$ \\
\hline Male/female (no. of subjects) & $15 / 2$ & $15 / 2$ & $7 / 1$ \\
\hline Mean age (range) (yr) & $33(18-59)$ & $29(20-55)$ & $27(19-42)$ \\
\hline Anterior cruciate & 2 & & \\
\hline \multicolumn{4}{|l|}{ Posterior cruciate* } \\
\hline Grade 3 & 9 & & \\
\hline$\leq$ Grade 2 & 4 & & \\
\hline
\end{tabular}


The Journal of BOnE \& JOINT SuRgERY • JBJS.ORG VOLUME 89-A · SUPPLEMENT $3 \cdot 2007$
Novel Methods for Diagnosis and Treatment of Posterolateral Rotatory Instability of the KneE

TABLE II Side-to-Side Differences in Displacement Shown by the Dial Test at $30^{\circ}$ of Knee Flexion and on Stress Radiographs in Each Group

\begin{tabular}{|lcc|}
\hline \multicolumn{1}{|c}{ Group } & \multicolumn{2}{c|}{ Mean Side-to-Side Difference $($ Range $)$} \\
\cline { 2 - 3 } & Dial Tet at 30 ${ }^{\circ}(\mathrm{deg})$ & Stress Radiograph* $(\mathrm{mm})$ \\
\hline Posterolateral rotatory instability & $17.0(12-22)$ & $6.2(3.4-11.8)$ \\
Normal control & $2.1(0-5)$ & $0.9(0.2-1.7)$ \\
Posterior cruciate injury & $3.9(1-6)$ & $1.5(0.7-2.2)$ \\
\hline
\end{tabular}

*Intergroup comparisons revealed that the side-to-side differences measured on the stress radiographs were significantly larger in the posterolateral-rotatory-instability group than in the normal control or posterior-cruciate-injury group ( $p=0.001$ for both comparisons). No significant difference was found between the normal control and posterior-cruciate-injury groups.

variability between measurements. The intraclass correlation coefficient can range from 0 to 1 , and a higher value means better agreement. In general, values of $>0.75$ are considered to represent good agreement, whereas values of $<0.40$ are considered to reflect poor agreement ${ }^{24}$.

The differences among the posterolateral-rotatoryinstability, normal control, and posterior-cruciate-injury groups were examined with use of the Kruskal-Wallis $\mathrm{H}$ test for nonparametric data. When a significant difference was detected, post hoc intergroup comparisons were made with use of the Mann-Whitney $U$ test. The association between the degree of side-to-side difference shown by the dial test and that shown by the stress radiograph in the posterolateral-rotatory-instability group was evaluated with use of the Pearson correlation test. In all analyses, a $\mathrm{p}$ value of $<0.05$ was considered significant.

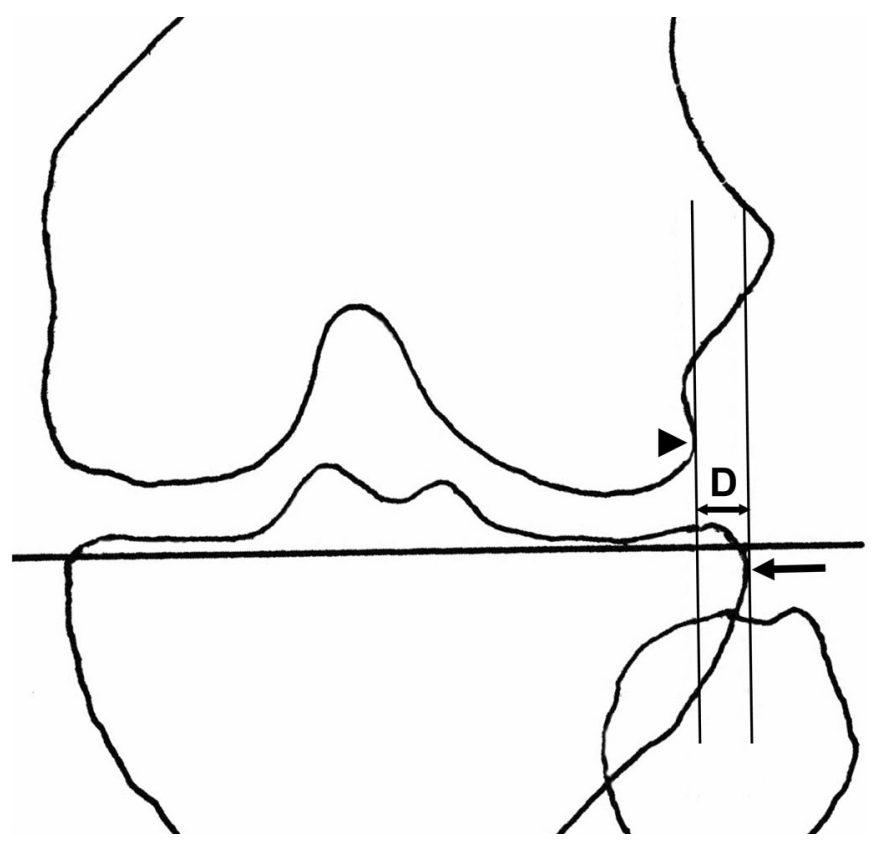

Fig. 2

Illustration of the measurement on the stress radiograph. Arrowhead = the lateral edge of the lateral femoral condyle, arrow = the lateral border of the lateral tibial condyle, $\mathrm{D}=$ the amount of displacement.

\section{Results}

The intrarater reliabilities of the measurements on the stress radiographs were almost perfect (intraclass correlation coefficient, 0.98 in the patient group and 0.99 in the normal control group). The maximum discrepancy among the measurements was $0.5 \mathrm{~mm}$.

Table II summarizes the results of the dial test and of the measurements on the stress radiographs in the three groups. In the posterolateral-rotatory-instability group, the side-to-side difference in displacement measured on the stress radiographs averaged $6.2 \mathrm{~mm}$, whereas it averaged $0.9 \mathrm{~mm}$ and $1.5 \mathrm{~mm}$, respectively, in the normal control and posterior-cruciate-injury groups (Figs. 3-A and 3-B). Intergroup comparisons revealed that side-to-side differences in displacement measured on the stress radiographs were significantly larger in the posterolateralrotatory-instability group than they were in the normal control and posterior-cruciate-injury groups ( $p=0.001$ for both comparisons). With the numbers studied, there was no significant difference in the stress-radiograph measurements between the normal control and posterior-cruciate-injury groups.

In the posterolateral-rotatory-instability group, the sideto-side differences in displacement measured on the stress radiographs were significantly correlated with the side-to-side angle differences demonstrated by the dial tests at $30^{\circ}$ of flexion (correlation coefficient $=0.44$ and $\mathrm{p}=0.01$ ).

\section{Anatomical Reconstruction of the Posterolateral Corner of the Knee with a Split Achilles Tendon Allograft Background}

$\mathrm{n}$ the basis of several anatomical and biomechanical studies $^{20,21,25-27}$, it has been generally agreed that the most consistent and important structures of the posterolateral corner of the knee are the popliteus tendon, the popliteofibular ligament, and the lateral collateral ligament. The posterolateral reconstruction procedures that are currently used to treat posterolateral instability, with respect to the principal anatomical structures, have been reported to be effective in providing satisfactory stability. However, these procedures have several shortcomings, including difficulty with concurrent reconstruction of the three important posterolateral structures 


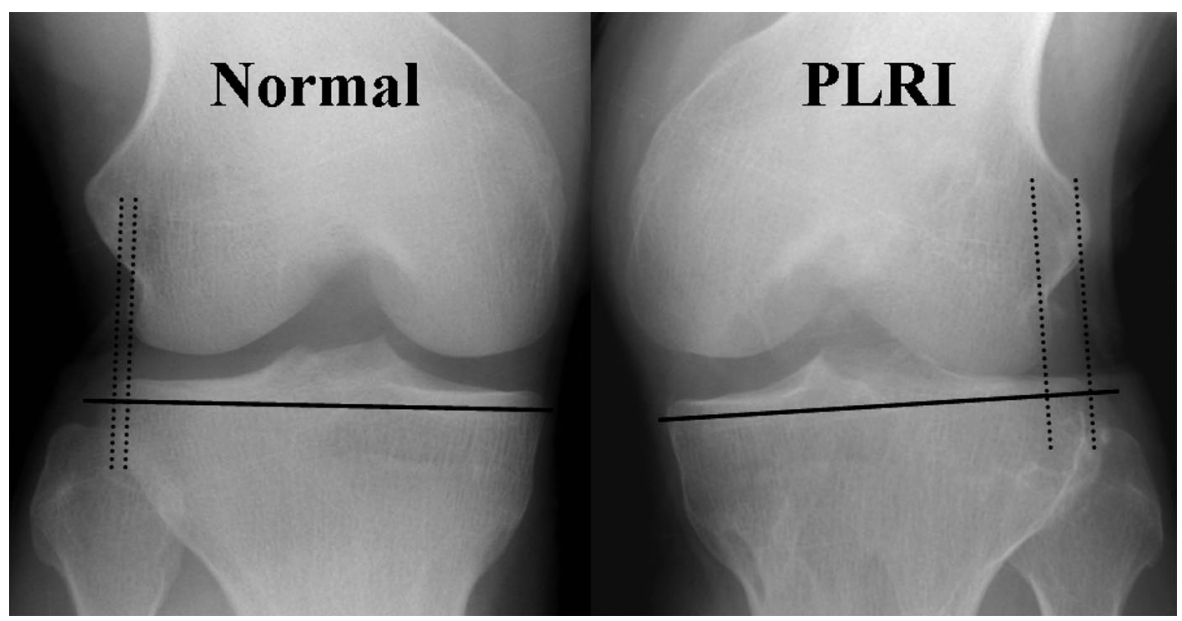

Fig. 3-A

Stress radiographs of a thirty-five-year-old man with posterolateral rotatory instability of the left knee demonstrate a side-to-side difference in displacement of $6.1 \mathrm{~mm}$.

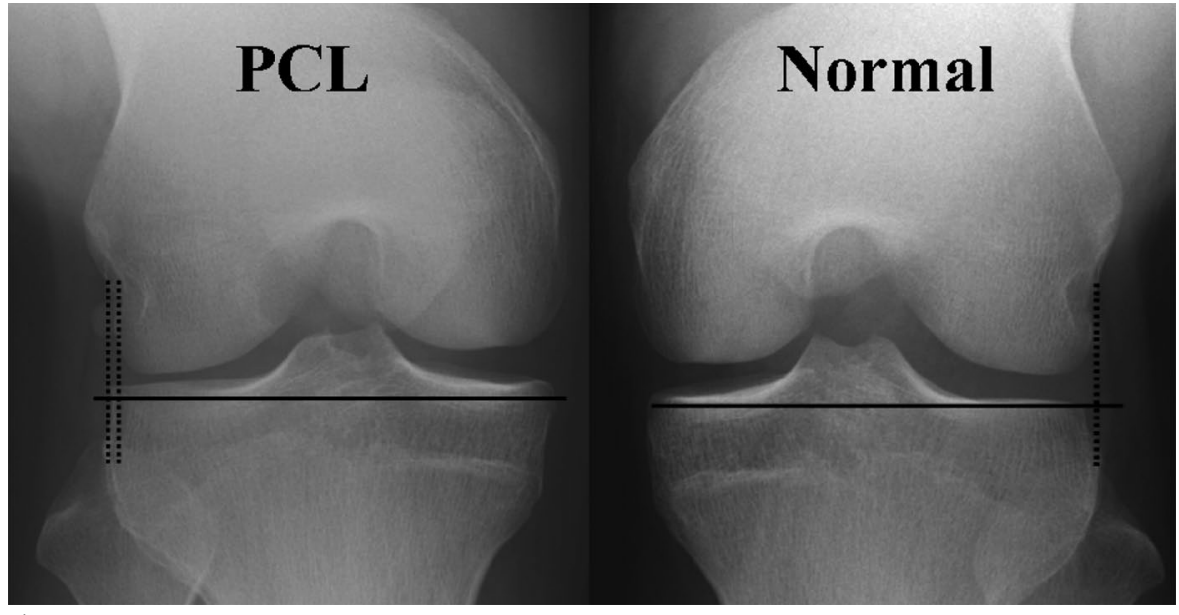

Fig. 3-B

Stress radiographs of a twenty-one-year-old man with an isolated posterior cruciate ligament injury of the right knee, but no evidence of posterolateral rotatory instability, demonstrate a sideto-side difference in displacement of $1.6 \mathrm{~mm}$.

and failure to restore the isometric point of each structure. In 2003, we reported a new reconstruction method for treating posterolateral rotatory instability that involves use of a split Achilles tendon allograft; this method allows concurrent reconstruction of the three important posterolateral structures and restores the isometry of the lateral collateral ligament and the popliteus complex ${ }^{7}$. In this report, we introduce the new reconstruction method and describe its clinical outcomes.

\section{Operative Technique}

Approach

With the knee flexed, a curvilinear incision through the skin and subcutaneous tissue is made beginning $5 \mathrm{~cm}$ proximal to the lateral epicondyle of the femur and extending just distal to the point between the fibular head and the Gerdy tubercle. Af- ter the common peroneal nerve is exposed below the fibular head, it is protected with a nerve sling. The interval between the biceps femoris and the iliotibial band is then developed with use of blunt dissection. The plane between the lateral head of the gastrocnemius and popliteus muscle and the posterior aspect of the capsule is also developed. The lateral head of the gastrocnemius is retracted posteriorly to allow identification of the target point, where the drill will exit during the tibial tunneling procedure. An incision is then made along the midportion of the iliotibial band over the lateral femoral epicondyle and is continued proximally and distally down to the popliteal hiatus to expose the insertion of the popliteus tendon. The anterior tibial muscle is released from the anterolateral aspect of the tibial crest just below the Gerdy tubercle.

A guide pin is then passed from just inferior to the Gerdy 


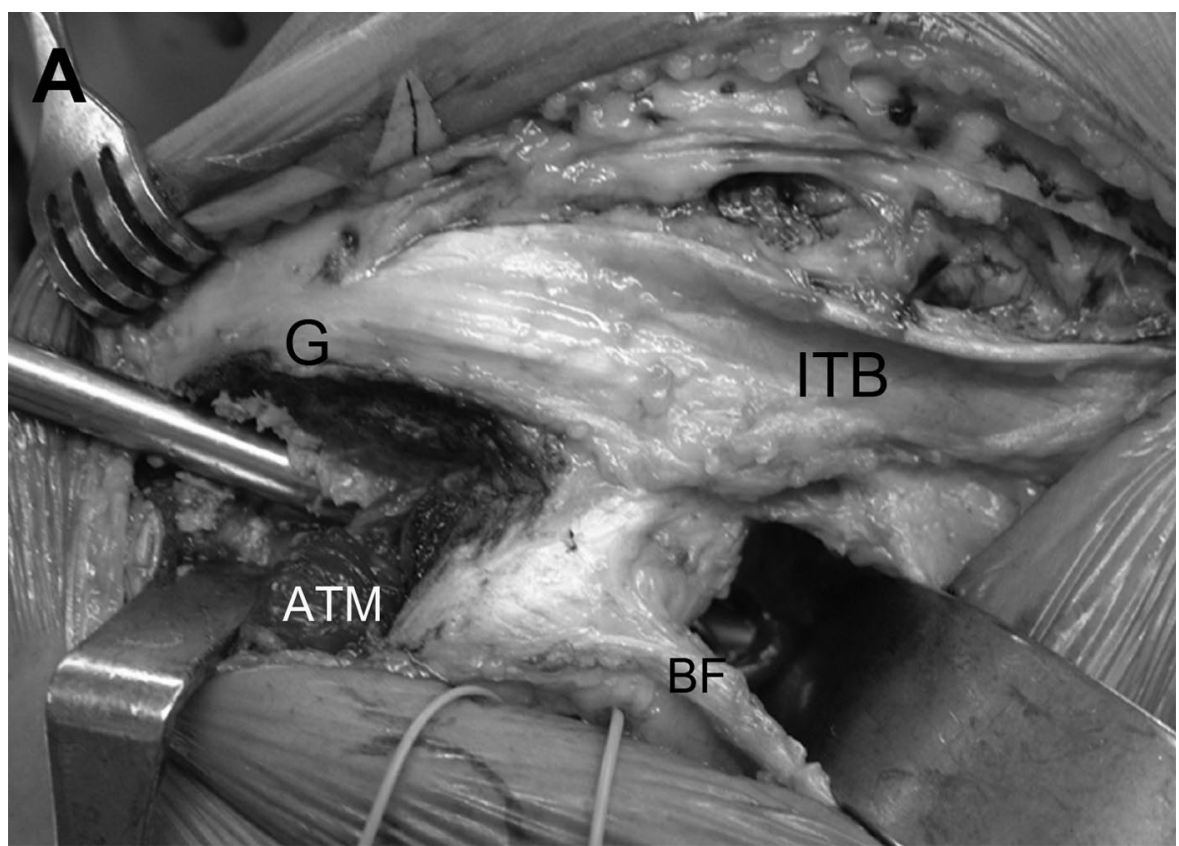

Fig. 4-A

Figs. 4-A through 4-E The technique of anatomical reconstruction of the posterolateral corner.

Fig. 4-A A tibial tunnel of $7 \mathrm{~mm}$ in diameter is established from just inferior to the Gerdy tubercle (G) to the desired point on the posterior aspect of the tibia anteroposteriorly, slightly oblique to the joint line, and 1.5 to $2 \mathrm{~cm}$ below the joint line. ITB = iliotibial band, ATM = anterior tibial muscle, and $\mathrm{BF}=$ biceps femoris tendon. (Reproduced, with modification, from: Lee MC, Park YK, Lee SH, Jo H, Seong SC. Posterolateral reconstruction using split Achilles tendon allograft. Arthroscopy. 2003;19:1043-9. Reprinted with permission.)

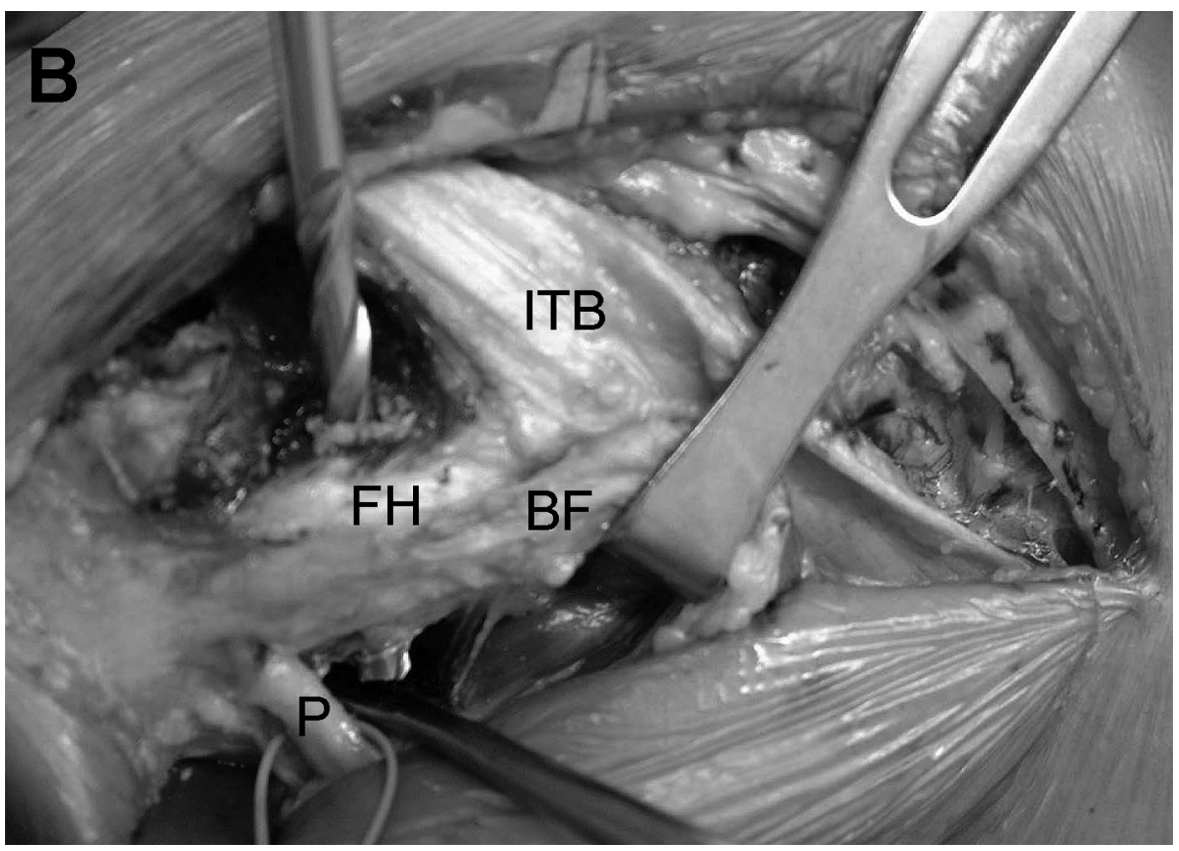

Fig. 4-B

A fibular tunnel of $6 \mathrm{~mm}$ in diameter is created from a point near the superior surface of the fibular head $(\mathrm{FH})$ to its posterior aspect and is directed posteroinferiorly. ITB = iliotibial band, $\mathrm{P}=$ peroneal nerve, and $\mathrm{BF}=$ biceps femoris tendon. 
The Journal of Bone \& JoInt Surgery • JBIS. ORG VOLUME 89-A · SUPPLEMENT $3 \cdot 2007$

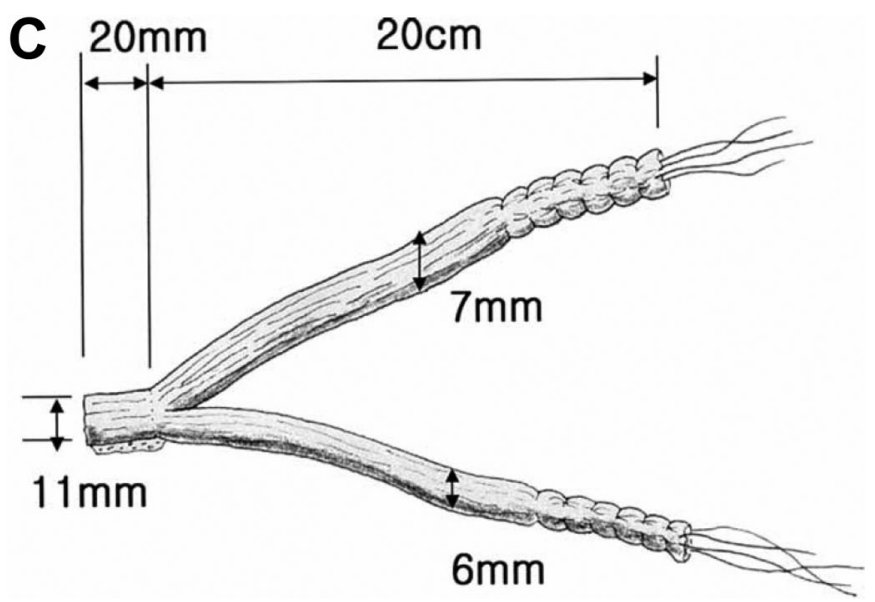

Fig. 4-C

The bone-plug portion of the allograft is shaped to $11 \times 20 \mathrm{~mm}$. The tendinous portion is prepared to provide sufficient length $(20 \mathrm{~cm})$ and is split longitudinally into two limbs, $7 \mathrm{~mm}$ and $6 \mathrm{~mm}$ in width. The free tendinous end of each limb is trimmed and rolled into a compact tube shape.

tubercle to the desired point on the posterior aspect of the tibia anteroposteriorly and slightly oblique to the joint line. After proper pin placement, 1.5 to $2 \mathrm{~cm}$ below the joint line, has been confirmed, a tunnel of $7 \mathrm{~mm}$ in diameter is established with a cannulated reamer (Fig. 4-A). From the point near the superior surface of the fibular head, a guide pin for a second tunnel is passed by aiming it posteroinferiorly. After an oblique tunnel of
Novel Methods for Diagnosis and Treatment of Posterolateral Rotatory Instability of the KneE

$6 \mathrm{~mm}$ in diameter is made with a cannulated reamer, a curet and a $7-\mathrm{mm}$ reamer are used to enlarge the tunnel. The tunnel should lie completely within the fibular head, as the neck is much too narrow to accept a reamer (Fig. 4-B).

The femoral tunnel is established along the most proximal portion of the popliteus insertion. A guide pin is placed initially, and a femoral tunnel, $11 \mathrm{~mm}$ in diameter and $20 \mathrm{~mm}$ in length, is created with a cannulated reamer.

We use fresh-frozen Achilles tendon allograft for the reconstruction. The bone-plug portion of the chosen allograft is fashioned into a $11 \times 20-\mathrm{mm}$ shape with a tapered tip, and the tendinous portion is prepared to allow a sufficient length of $20 \mathrm{~cm}$ and is split longitudinally into 2 limbs, $7 \mathrm{~mm}$ and $6 \mathrm{~mm}$ in width (Fig. 4-C). The free tendinous end of each limb is trimmed and is rolled into a compact tube shape and prevented from unrolling with number-1-0 nonabsorbable suture. We encircle one-fourth of the entire circumference of the tendon with each throw. The suture forms a criss-crossing weave that further tapers the tendon when pretension is applied to it, making it easier to draw it through the formed tunnels.

\section{Tunnel Passage and Graft Fixation}

The tapered bone plug of the allograft is placed into the femoral tunnel with the cancellous bone facing upward and is secured with an appropriately sized cannulated interference screw (Fig. 4-D). After the tendinous portion of each limb is passed below the iliotibial band and the biceps femoris, the $7-\mathrm{mm}$ anterior limb is passed through the tibial tunnel, from posterior to ante-

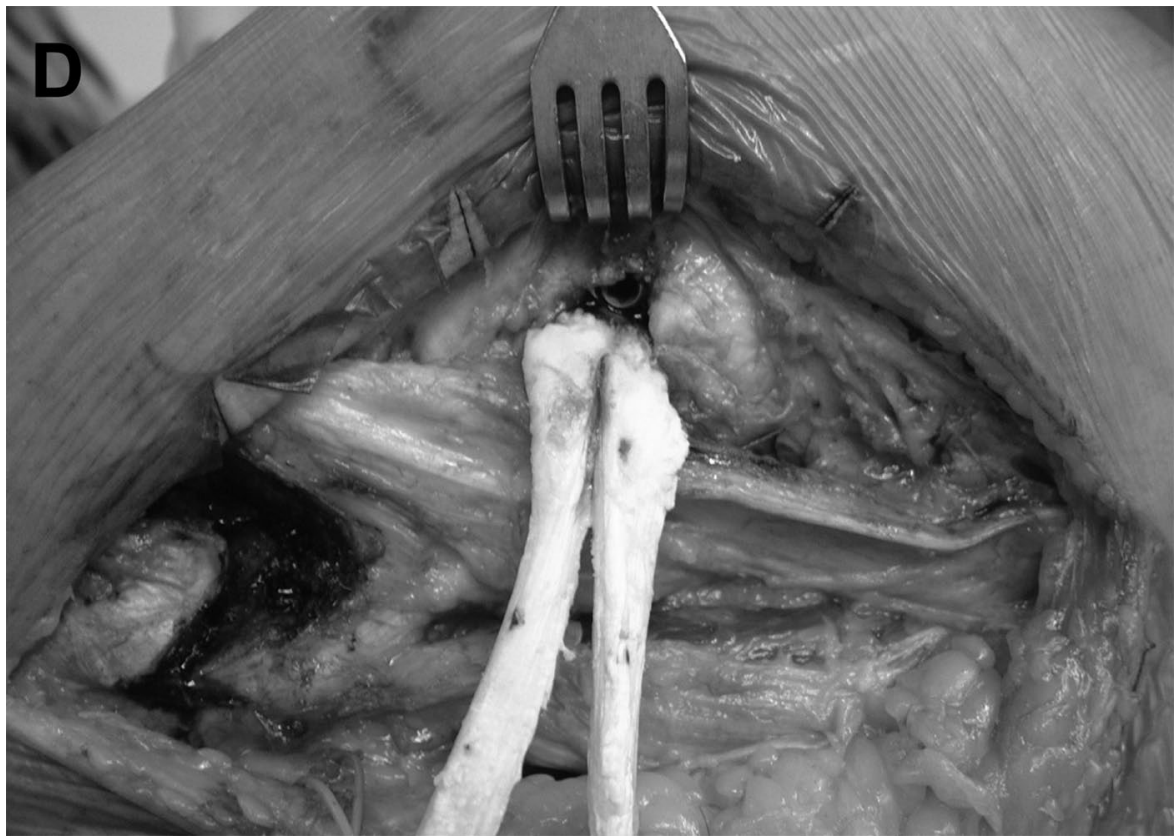

Fig. 4-D

The tapered bone plug of the allograft is placed into the anteroinferior side tunnel of the femur with the cancellous bone facing upward and is secured with an appropriately sized cannulated interference screw. 
The Journal of Bone \& JoInt Surgery • JBIS. ORG VOLUME 89-A · SUPPLEMENT $3 \cdot 2007$
Novel Methods for Diagnosis and Treatment

of Posterolateral Rotatory Instability of the KneE

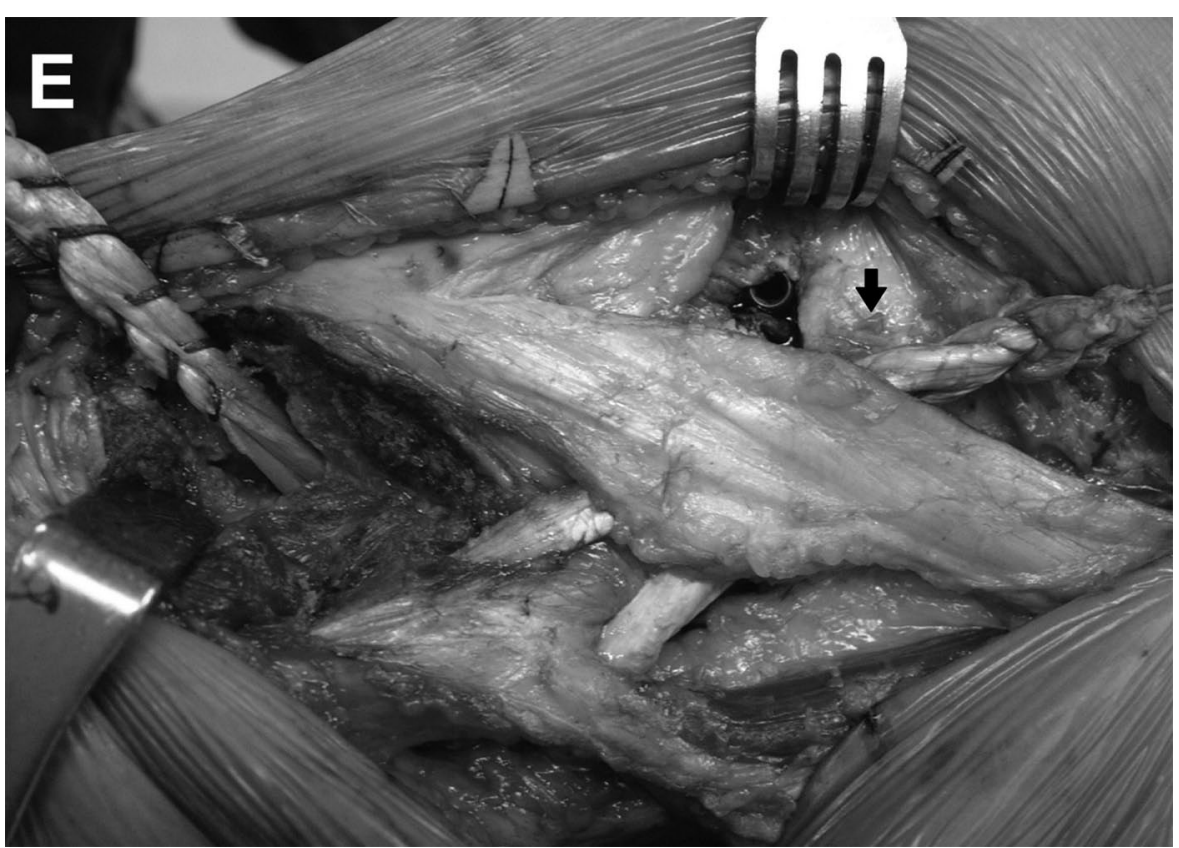

Fig. 4-E

The 7-mm limb is passed through the tibial tunnel from posterior to anterior to recreate the popliteus. The 6-mm limb is passed through the fibular tunnel to just reach the posterior aspect of the lateral femoral epicondyle, which is the isometric point of the lateral collateral ligament. A fixed position of the 6-mm limb is secured with staples placed near the origin of the original lateral collateral ligament (arrow).

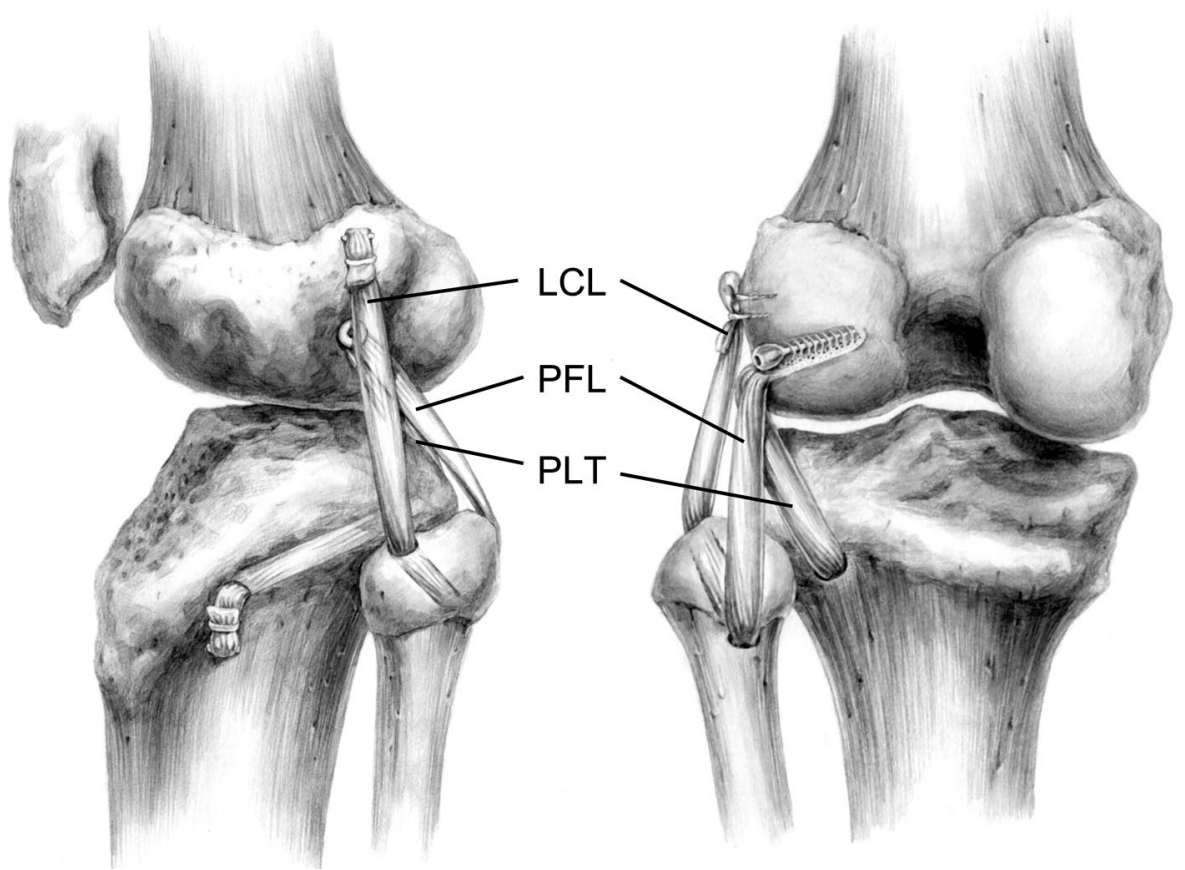

Fig. 5

Illustration of the reconstructed posterolateral corner of the knee. $L C L=$ lateral collateral ligament, PFL = popliteofibular ligament, and PLT = popliteus. 
The Journal of Bone \& JOINT SURGERY · JBJS.ORG VOLUME 89-A · SUPPLEMENT $3 \cdot 2007$
Novel Methods for Diagnosis and Treatment

of Posterolateral Rotatory Instability of the Knee

\begin{tabular}{|c|c|c|c|c|c|}
\hline Case & $\begin{array}{l}\text { Gender, } \\
\text { Age }(y r)\end{array}$ & $\begin{array}{l}\text { Cause } \\
\text { of Injury }\end{array}$ & Site & Combined Injury & Combined Surgery \\
\hline 1 & M, 35 & Traffic accident & $\mathrm{L}$ & $\begin{array}{l}\text { Posterior cruciate and medial collateral } \\
\text { ligaments }\end{array}$ & $\begin{array}{l}\text { Medial collateral repair, posterior } \\
\text { cruciate reconstruction }\end{array}$ \\
\hline 2 & M, 35 & Traffic accident & $\mathrm{L}$ & Posterior cruciate ligament & Posterior cruciate reconstruction \\
\hline 3 & M, 38 & Sports & $\mathrm{R}$ & Anterior cruciate ligament & Anterior cruciate reconstruction \\
\hline 4 & M, 22 & Sports & L & Posterior cruciate ligament (grade $1 *$ ) & Medial open wedge osteotomy \\
\hline 5 & M, 23 & Sports & $\mathrm{L}$ & Posterior and anterior cruciate ligaments & $\begin{array}{l}\text { Anterior and posterior cruciate } \\
\text { reconstructions }\end{array}$ \\
\hline 6 & M, 22 & Fall & $\mathrm{L}$ & None & \\
\hline 7 & M, 59 & Sports & $\mathrm{L}$ & $\begin{array}{l}\text { Posterior cruciate, anterior cruciate, and } \\
\text { medial collateral ligaments }\end{array}$ & $\begin{array}{l}\text { Anterior and posterior cruciate } \\
\text { reconstructions, medial collateral } \\
\text { repair, posterior oblique ligament } \\
\text { advancement }\end{array}$ \\
\hline 8 & M, 43 & Traffic accident & $\mathrm{R}$ & Posterior and anterior cruciate ligaments & $\begin{array}{l}\text { Anterior and posterior cruciate } \\
\text { reconstructions }\end{array}$ \\
\hline 9 & M, 26 & Traffic accident & $\mathrm{L}$ & Posterior cruciate ligament & Posterior cruciate reconstruction \\
\hline 10 & M, 23 & Sports & $\mathrm{R}$ & Posterior cruciate ligament & Posterior cruciate reconstruction \\
\hline 11 & M, 18 & Sports & $\mathrm{L}$ & Posterior cruciate ligament & Posterior cruciate reconstruction \\
\hline 12 & M, 23 & Traffic accident & L & Posterior cruciate ligament & Posterior cruciate reconstruction \\
\hline
\end{tabular}

* Grade 1-0 to $5 \mathrm{~mm}$ of posterior translation, Grade 2-5 to $10 \mathrm{~mm}$ of posterior translation, and Grade $3>10 \mathrm{~mm}$ of posterior translation, according to the system of Harner and Hoher ${ }^{39}$.

rior, with use of a silicone tendon-passer to recreate the popliteus. The 6-mm limb, located posterior to the 7-mm limb, is passed under the biceps and through the fibular tunnel from posteroinferior to anterosuperior and then passed under the iliotibial band to just reach the posterior aspect of the lateral femoral epicondyle, which is the estimated isometric point of the lateral collateral ligament. The posterior portion of the $6-\mathrm{mm}$ limb (before it passes through the fibular tunnel) is designed to recreate the popliteofibular ligament, and the anterior portion (after it passes through the fibular tunnel) is designed to recreate the lateral collateral ligament (Fig. 4-E). After the graft tension has been checked throughout the range of knee motion and after pretension has been applied, the end of the 7-mm limb is fixed directly to the tibia near the outlet of the tibial tunnel with use of a double-staple fixation technique with the knee held in $30^{\circ}$ of flexion and in neutral rotation. The end of the 6$\mathrm{mm}$ limb is fixed to the origin of the lateral collateral ligament, just posterior to the center of the lateral epicondyle and posterior to the femoral tunnel, with use of a double-staple fixation technique (Fig. 5).

\section{Postoperative Rehabilitation}

After the surgery, the knee is placed in an immobilizer in full extension for three to four weeks, during which time weightbearing is not allowed. Isometric quadriceps-muscle exercises are started immediately. A range-of-motion program and closed-chain kinetic exercises are begun at four weeks, and a standard cruciate-ligament rehabilitation program is then followed for the next six to twelve months.

\section{Materials and Methods}

The institutional review board of our hospital granted approval for a clinical study of the results of this technique, and all patients gave informed consent for the use of their medical information. Between January 2002 and March 2006, thirtytwo consecutive patients with posterolateral rotatory instability were treated with the new reconstruction method, and data on all of these patients were entered prospectively into a database designed to record patient demographics and characteristics, radiographic measurements, findings of the physical examination, and preoperative and postoperative clinical outcome scores, including the Tegner activity level ${ }^{28}$ and the Lysholm score ${ }^{29}$. Twelve knees in twelve patients who were followed for more than two years after the surgery were included in this study. All patients were male, and the mean age was 30.6 years (range, eighteen to fifty-nine years). The mean time from the injury to the surgery was eighteen months (range, two months to sixteen years), and the mean duration of the follow-up period was thirty-seven months (range, twenty-six to fifty months). The clinical details are shown in Table III.

To evaluate the stability of the posterolateral corner after the procedure, we compared the preoperative and postoperative results of the dial tests at $30^{\circ}$ and $90^{\circ}$ of knee flexion and the preoperative and postoperative results of the varus stress tests at 
The Journal of Bone \& JoInt Surgery - JBJS.org VOLUME 89-A · SUPPLEMENT $3 \cdot 2007$
Novel Methods for Diagnosis and Treatment of Posterolateral Rotatory Instability of the KneE
TABLE IV Comparison of Preoperative and Postoperative Physical Findings to Assess Posterolateral Stability of the Knee in the Twelve Patients in the Study of the Reconstruction Procedure

\begin{tabular}{|lcc|}
\hline & Preoperative* & Postoperative* \\
\hline Dial test at $30^{\circ}$ of flexion & & \\
$\quad$ Side-to-side difference $>10^{\circ}$ & 12 & 0 \\
Mean side-to-side difference (deg) & 16 & -1 \\
Dial test at $90^{\circ}$ of flexion & & \\
$\quad$ Side-to-side difference $>10^{\circ}$ & 8 & 0 \\
Mean side-to-side difference (deg) & 12 & 0 \\
Varus stress test at $0^{\circ}$ of flexion & & \\
Grade 0 & 4 & 11 \\
Grade 1 & 4 & 1 \\
Grade 2 & 3 & 0 \\
Grade 3 & 1 & 0 \\
Varus stress test at 30 of flexion & & \\
Grade 0 & 0 & 10 \\
Grade 1 & 3 & 2 \\
Grade 2 & 7 & 0 \\
Grade 3 & 2 & 0 \\
Pos. posterolateral drawer test & 12 & 1 \\
Pos. reverse pivot shift test & 8 & 0 \\
Pos. external rotation recurvatum test & 7 & 0 \\
\hline
\end{tabular}

*The values are given as the number of patients, except for the mean side-to-side differences in displacement demonstrated by the dial tests, which are given in degrees.

$0^{\circ}$ and $30^{\circ}$ of knee flexion. In addition, we assessed whether the posterolateral drawer test, the reverse pivot shift test, and the external rotation recurvatum test were positive preoperatively and postoperatively. To assess the clinical outcomes, we compared the preoperative and postoperative ranges of motion of the knee, Tegner activity levels, and Lysholm scores.

The statistical comparisons between the preoperative and postoperative functional outcomes were made with use of the Wilcoxon signed-rank test, and a $p$ value of $<0.05$ was considered significant.

\section{Results}

At the time of final follow-up, all twelve patients had significant improvements in the stability of the posterolateral corner of the knee (Table IV). The mean preoperative Lysholm score was 39.5 points, and it improved to 78.1 points at the time of the latest follow-up $(\mathrm{p}<0.01)$. The mean Tegner score improved from 1.9 points to 3.9 points $(\mathrm{p}<0.01)$. All but one patient had a nearly full active range of motion postoperatively. One patient, who was diagnosed as having reflex sympathetic dystrophy, had $10^{\circ}$ to $120^{\circ}$ of passive knee motion at two years after the surgery. He reported having considerable pain during daily activity and had poor clinical outcome scores (26 points on the Lysholm scale and a grade- 0 Tegner activity level) at the time of the latest follow-up.

\section{Discussion}

W e have described new methods for the diagnosis and treatment of posterolateral rotatory instability of the knee. We developed the external rotation-valgus stress radiograph at $30^{\circ}$ of knee flexion as a diagnostic tool on the basis of biomechanical studies and found it to be a practical and valuable method for objective documentation of posterolateral rotatory instability of the knee. To the best of our knowledge, this represents the first application of stress radiography for the diagnosis of posterolateral rotatory instability of the knee.

Several physical examination tests have been introduced to detect posterolateral rotatory instability of the knee $e^{18,19,30,31}$; these include the dial test performed with the knee flexed $30^{\circ}$ and $90^{\circ 31,32}$. However, these tests are subjective, and we believe that they are highly dependent on the examiner's judgment in many cases. Among the examinations, the dial test at $30^{\circ}$ of flexion is known to be specific for posterolateral rotatory instability; however, it is our anecdotal experience that accurate measurement of the thigh-foot angle is difficult to perform, and the interrater and intrarater variability of this examination can be considerable. Among the imaging tools, magnetic resonance imaging is known to be helpful for the diagnosis of a posterolateral corner injury, especially an acute injury. However, the reported sensitivity of magnetic resonance imaging, used with a standard protocol, for the detection of all posterolateral corner structures has been found to be unsatisfactory; even with use of a specialized protocol, its sensitivity has been found to be lower than that for the detection of a cruciate ligament injury ${ }^{33}$. Furthermore, because magnetic resonance imaging provides static images, it might not be able to demonstrate the true instability of the knee, particularly in chronic cases.

In this study, we found that the degree of side-to-side difference demonstrated by the dial test was significantly and positively correlated with the amount of side-to-side difference measured on the stress radiograph. This finding suggests that it might be possible to grade the amount of instability seen on the stress radiograph. However, we do not believe that the present study was comprehensive enough to allow us to propose a grading system because accurate measurement of the thigh-foot angle during the dial test is inconsistent, even with repeated measurements by two examiners. Moreover, the number of subjects enrolled in the present study was limited. Nevertheless, as the displacements on the stress radiographs in the posterolateral-rotatory-instability group were significantly larger than those in either the control or the posteriorcruciate-injury group, it is our opinion that the external rotation-valgus stress radiograph can be of value in the diagnosis of posterolateral rotatory instability of the knee.

Since several authors have demonstrated that failure to restore the posterolateral corner is an important cause of failure of both a posterior cruciate ligament and an anterior cruciate ligament reconstruction ${ }^{14,16,17}$, great efforts have been made to find the appropriate treatment for a posterolateral corner in- 
The Journal of Bone \& JoINT SURGERY $\cdot$ JBJS.ORG Volume $89-\mathrm{A} \cdot$ SUPplement $3 \cdot 2007$
Novel Methods for Diagnosis and Treatment of Posterolateral Rotatory Instability of the Knee jury. The surgical approach used to restore stability to the injured posterolateral aspect of the knee has evolved substantially. Early procedures involved the advancement of the femoral attachment of the posterolateral structures. Hughston and Jacobson reported improved clinical results in ninety-five patients who had undergone proximal bone-block advancement of the posterolateral complex for treatment of chronic posterolateral instability ${ }^{5}$. However, this advancement procedure did not restore isometry; therefore, many patients had loosening with time. Clancy recommended biceps tenodesis to reconstruct the posterolateral corner by transferring the biceps tendon to the anterior aspect of the lateral epicondyle while leaving its distal attachment to the fibula intact ${ }^{34}$. However, this reconstruction did not anatomically recreate the popliteus or the popliteofibular ligament and, thus, represented only a partial reconstruction of the posterolateral corner. Subsequent procedures involved the creation of an extra-articular sling to restore posterolateral stability. Müller introduced the popliteal bypass procedure, in which a graft was placed through a tibial tunnel exiting at the posterolateral corner of the tibia and secured to the anterior aspect of the lateral femoral condyle ${ }^{8}$. Albright and Brown reported on the posterolateral corner sling procedure, which involved the use of an autograft or an allograft to approximate the reconstruction of the popliteus tendon ${ }^{2}$. More recent studies have revealed that the lateral collateral ligament, the popliteus tendon, and the popliteofibular ligament are the three key structures in the posterolateral corner $^{27,35}$. Interest has focused on the popliteal complex, particularly the popliteofibular ligament, and several research efforts have improved our understanding of the role of the popliteofibular ligament ${ }^{26,36}$. Consequently, there have been several reports on the anatomical reconstruction of the lateral collateral ligament and the popliteal complex ${ }^{9,11,37}$. However, these concurrent reconstructions of all structures failed to restore the optimal isometric points of each structure. To address these limitations, we used a split Achilles tendon allograft to concurrently reconstruct the three important structures and restore their isometry ${ }^{7}$. In our procedure, the posterior portion of the 6-mm limb (before it is passed through the fibular tunnel) was designed to recreate the popliteofibular ligament and the anterior portion (after it is passed through the fibular tunnel) was designed to recreate the lateral collateral ligament with separate isometric points. In addition, the 7-mm limb was planned to restore the popliteus tendon as closely as possible to its original position. In addition, this technique does not require an additional incision for a pull-out suture, which is needed with some of the other techniques ${ }^{11,38}$.

Although the number of patients in our study was limited, the results after a minimum of two years of followup suggest that our anatomical reconstruction is a reliable method that provides excellent stability and satisfactory clinical results. We believe that the poor clinical outcome of one patient stemmed from reflex sympathetic dystrophy and not from the ligament reconstruction per se. None of the other thirty-one patients who had been treated with this procedure had a similar outcome.

Recently, several procedures designed to concurrently reconstruct the three major structures of the posterolateral corner have been introduced ${ }^{6,10,12}$. These procedures correspond to ours in terms of restoration of the isometric points of each structure. Hopefully, the current reconstructive procedures will allow us to achieve outcomes that will remain satisfactory after longer follow-up.

Corresponding author:

Myung Chul Lee, MD, PhD

Department of Orthopedic Surgery, Seoul National University Hospital, 28 Yongondong, Chongnogu, 110-744, Seoul, South Korea. E-mail address: leemc@snu.ac.kr

\section{References}

1. LaPrade RF, Wentorf $F$. Diagnosis and treatment of posterolateral knee injuries. Clin Orthop Relat Res. 2002;402:110-21.

2. Albright JP, Brown AW. Management of chronic posterolateral rotatory instability of the knee: surgical technique for the posterolateral corner sling procedure. Inst Course Lect. 1998;47:369-78.

3. LaPrade RF, Terry GC. Injuries to the posterolateral aspect of the knee. Association of anatomic injury patterns with clinical instability. Am J Sports Med. 1997;25:433-8.

4. Fanelli GC, Edson CJ. Combined posterior cruciate ligament-posterolateral reconstructions with Achilles tendon allograft and biceps femoris tendon tenodesis: 2- to 10-year follow-up. Arthroscopy. 2004;20:339-45.

5. Hughston JC, Jacobson KE. Chronic posterolateral rotatory instability of the knee. J Bone Joint Surg Am. 1985;67:351-9.

6. LaPrade RF, Johansen S, Wentorf FA, Engebretsen L, Esterberg JL, Tso A. An analysis of an anatomical posterolateral knee reconstruction: an in vitro biomechanical study and development of a surgical technique. Am J Sports Med. 2004;32:1405-14.

7. Lee MC, Park YK, Lee SH, Jo H, Seong SC. Posterolateral reconstruction using split Achilles tendon allograft. Arthroscopy. 2003;19:1043-9.

8. Müller W. Die Rotationsinstabilitat am kniegelenk. Hefte Unfallhk. 1990;125:51-68.

9. Noyes FR, Barber-Westin SD. Surgical reconstruction of severe chronic pos- terolateral complex injuries of the knee using allograft tissues. Am J Sports Med. 1995;23:2-12.

10. Sekiya JK, Kurtz CA. Posterolateral corner reconstruction of the knee: surgical technique utilizing a bifid Achilles tendon allograft and a double femoral tunnel. Arthroscopy. 2005;21:1400.

11. Veltri DM, Warren RF. Treatment of acute and chronic injuries to the posterolateral and lateral knee. Oper Tech Sports Med. 1996;4:174-81.

12. Yoon $\mathrm{KH}$, Bae DK, Ha JH, Park SW. Anatomic reconstructive surgery for posterolateral instability of the knee. Arthroscopy. 2006;22:159-65.

13. Torg JS, Barton TM, Pavlov H, Stine R. Natural history of the posterior cruciate ligament-deficient knee. Clin Orthop Relat Res. 1989;246:208-16.

14. Harner CD, Vogrin TM, Hoher J, Ma CB, Woo SL. Biomechanical analysis of a posterior cruciate ligament reconstruction. Deficiency of the posterolateral structures as a cause of graft failure. Am J Sports Med. 2000; 28:32-9.

15. Kannus P. Nonoperative treatment of grade II and III sprains of the lateral ligament compartment of the knee. Am J Sports Med. 1989;17:83-8.

16. LaPrade RF, Muench $C$, Wentorf F, Lewis JL. The effect of injury to the posterolateral structures of the knee on force in a posterior cruciate ligament graft: a biomechanical study. Am J Sports Med. 2002;30:233-8.

17. LaPrade RF, Resig S, Wentorf $F$, Lewis JL. The effects of grade III posterolateral knee complex injuries on anterior cruciate ligament graft force. A biomechan- 
The Journal of Bone \& JOINT SURGERY • JBJS.org VOLUME 89-A · SUPPLEMENT $3 \cdot 2007$
Novel Methods for Diagnosis and Treatment

of Posterolateral Rotatory Instability of the Knee ical analysis. Am J Sports Med. 1999;27:469-75.

18. Hughston JC, Norwood LA. The posterolateral drawer test and external rotational recurvatum test for posterolateral rotatory instability of the knee. Clin Orthop Relat Res. 1980;147:82-7.

19. Jakob RP, Hassler $\mathrm{H}$, Staeubli HU. Observations on rotatory instability of the lateral compartment of the knee. Experimental studies on the functional anatomy and the pathomechanism of the true and the reversed pivot shift sign. Acta Orthop Scand Suppl. 1981;191:1-32.

20. Gollehon DL, Torzilli PA, Warren RF. The role of the posterolateral and cruciate ligaments in the stability of the human knee. A biomechanical study. J Bone Joint Surg Am. 1987;69:233-42.

21. Grood ES, Stowers SF, Noyes FR. Limits of movement in the human knee. Effect of sectioning the posterior cruciate ligament and posterolateral structures. J Bone Joint Surg Am. 1988;70:88-97.

22. Veltri DM, Deng XH, Torzilli PA, Warren RF, Maynard MJ. The role of the cruciate and posterolateral ligaments in stability of the knee. A biomechanical study. Am J Sports Med. 1995;23:436-43.

23. Shino K, Horibe $S$, Ono K. The voluntarily evoked posterolateral drawer sign in the knee with posterolateral instability. Clin Orthop Relat Res. 1987;215:179-86.

24. Fleiss JL. Statistical methods for rates and proportions. 2nd ed. New York: Wiley; 1981.

25. Veltri DM, Deng XH, Torzilli PA, Maynard MJ, Warren RF. The role of the popliteofibular ligament in stability of the human knee. A biomechanical study. Am J Sports Med. 1996;24:19-27.

26. Sugita T, Amis AA. Anatomic and biomechanical study of the lateral collateral and popliteofibular ligaments. Am J Sports Med. 2001;29:466-72.

27. Maynard MJ, Deng X, Wickiewicz TL, Warren RF. The popliteofibular ligament. Rediscovery of a key element in posterolateral stability. Am J Sports Med. 1996;24:311-6.

28. Tegner Y, Lysholm J. Rating systems in the evaluation of knee ligament injuries. Clin Orthop Relat Res. 1985;198:43-9.

29. Lysholm J, Gillquist J. Evaluation of knee ligament surgery results with special emphasis on use of a scoreing scale. Am J Sports Med. 1982;10:150-4.

30. DeLee JC, Riley MB, Rockwood CA. Acute straight lateral instability of the knee. Am J Sports Med. 1983;11:404-11.

31. Veltri DM, Warren RF. Anatomy, biomechanics, and physical findings in posterolateral knee instability. Clin Sports Med. 1994;13:599-614.

32. Loomer RL. A test for knee posterolateral rotatory instability. Clin Orthop Relat Res. 1991;264:235-8.

33. Yu JS, Salonen DC, Hodler J, Haghighi P, Trudell D, Resnick D. Posterolateral aspect of the knee: improved MR imaging with a coronal oblique technique. Radiology. 1996;198:199-204.

34. Clancy WG Jr. Repair and reconstruction of the posterior cruciate ligament. In: Chapman MW, editor. Operative orthopaedics. Vol 3. Philadelphia: JB Lippincott; 1998. p 1651-65.

35. LaPrade RF, Ly TV, Wentorf FA, Engebretsen L. The posterolateral attachments of the knee: a qualitative and quantitative morphologic analysis of the fibular collateral ligament, popliteus tendon, popliteofibular ligament, and lateral gastrocnemius tendon. Am J Sports Med. 2003;31:854-60.

36. Shahane SA, Ibbotson C, Strachan R, Bickerstaff DR. The popliteofibular ligament. An anatomical study of the posterolateral corner of the knee. J Bone Joint Surg Br. 1999;81:636-42

37. Larson RV. Isometry of the lateral collateral and popliteofibular ligaments and techniques for reconstruction using a free semitendinosus tendon graft. Ope Tech Sports Med. 2001;9:84-90.

38. Latimer HA, Tibone JE, EIAttrache NS, McMahon PJ. Reconstruction of the lat eral collateral ligament of the knee with patellar tendon allograft. Report of a new technique in combined ligament injuries. Am J Sports Med. 1998;26:656-62.

39. Harner CD, Hoher J. Evaluation and treatment of posterior cruciate ligament injuries. Am J Sports Med. 1998;26:471-82. 